\title{
Advanced optical imaging in living embryos
}

\author{
Christie A. Canaria $\cdot$ Rusty Lansford
}

Received: 4 April 2010/Revised: 12 June 2010/ Accepted: 15 June 2010/Published online: 8 July 2010

(C) The Author(s) 2010. This article is published with open access at Springerlink.com

\begin{abstract}
Developmental biology investigations have evolved from static studies of embryo anatomy and into dynamic studies of the genetic and cellular mechanisms responsible for shaping the embryo anatomy. With the advancement of fluorescent protein fusions, the ability to visualize and comprehend how thousands to millions of cells interact with one another to form tissues and organs in three dimensions $(x y z)$ over time $(t)$ is just beginning to be realized and exploited. In this review, we explore recent advances utilizing confocal and multi-photon time-lapse microscopy to capture gene expression, cell behavior, and embryo development. From choosing the appropriate fluorophore, to labeling strategy, to experimental set-up, and data pipeline handling, this review covers the various aspects related to acquiring and analyzing multi-dimensional data sets. These innovative techniques in multidimensional imaging and analysis can be applied across a number of fields in time and space including protein dynamics to cell biology to morphogenesis.
\end{abstract}

Keywords Confocal - Two-photon · Microscopy · Time-lapse imaging $\cdot$ Embryogenesis

\section{Introduction}

Solving the mysteries of how progenitor cells assume specific cell fates and then assemble into functional organs remains a fundamental challenge in biology. Recent research has revealed that complex signaling,

C. A. Canaria · R. Lansford $(\bowtie)$

California Institute of Technology,

1200 E. California Blvd, MC 139-74, Pasadena, CA 91125, USA

e-mail: rusty@caltech.edu transcriptional, and translational networks that regulate key cellular decisions are essential for proper embryogenesis. New imaging tools that permit 4D imaging are being refined and applied to visualize how molecular, cellular, and mechanical input drives pattern formation in model organisms amenable to dynamic imaging.

An essential requirement of time-lapse imaging is that the specimen continues to live and to function normally throughout the course of image acquisition. Successfully culturing a specimen is made much more difficult by the requirements of imaging: the specimen must be incubated under conditions that permit normal development, within the working distance of the objective, and able to withstand the barrage of photons used to illuminate the specimen for imaging. Equally important, utilizing the appropriate fluorescent reporters and microscope techniques are vital in successfully capturing the dynamic processes of interest.

Developmental biology is a study of spatiotemporal change: molecules diffuse, proteins are trafficked, cells divide, and organs develop along the arrow of time. In this review, we highlight a few instances that show how light microscopy is used to explore ever-changing biological processes as they occur in real time in living animal model systems.

The evolution of imaging

Traditionally, our understanding of development biology has been rooted in the fixation and study of embryonic samples. Detailed microscopic scrutiny of static specimen at varying ages allowed for anatomical assessment in tissue development. During the 1970s, there was a shift in the application of antibodies for biological imaging [1]. Fluorescently tagged antibodies [2] were being applied to cells, and whole new cytoskeletal vistas were revealed [3]. 
Coincidentally, during the late 70 s and early 80 s, new fluorophores reporting cellular conditions, including intracellular calcium concentrations $[1,4]$ were experiencing increased usage. These research breakthroughs ignited the advent of the modern confocal microscope $[1,5,6]$. Continued efforts in imaging optics and technology gave rise to spinning disk microscopy [7-9] and two-photon excitation (2PE) microscopy [10-15].

Epifluorescence microscopy is an approachable method for dynamically imaging embryo development, as

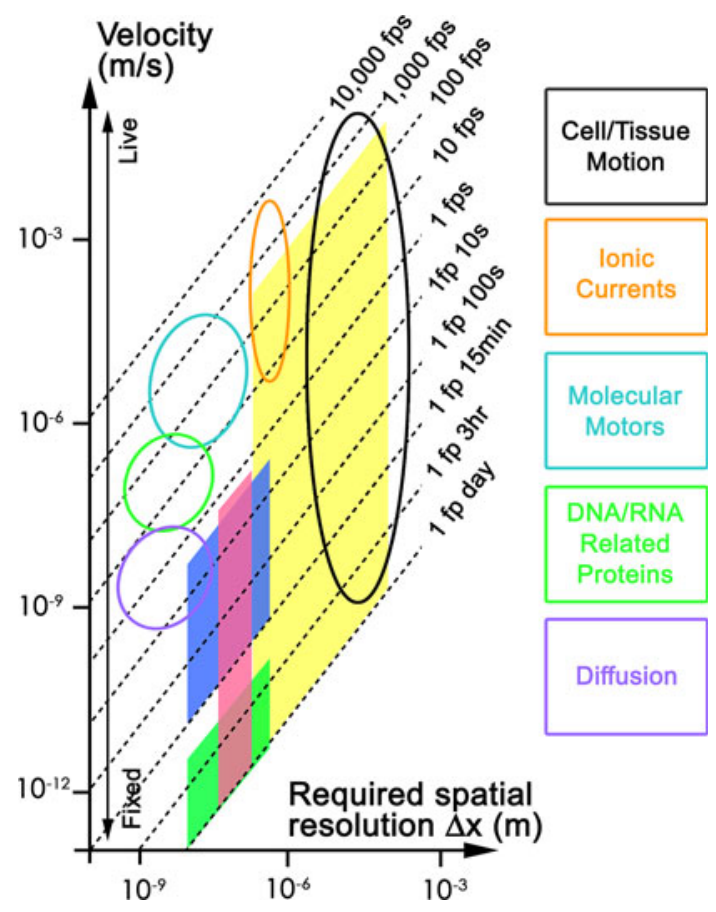

Fig. 1 Optical imaging techniques for dynamic biological processes. Dashed lines represent the frame rate needed to resolve dynamic objects based on their velocity and their required spatial resolution. Shaded boxes represent areas covered by various microscopy modalities. Color-coded ovals and open boxes outline the resolutions required for some common biological processes. The yellow box covers commercially available techniques (widefield, confocal, 2PE, spinning disk). The blue box covers STED; green box (F-) PALM/ STORM; pink box $4 \mathrm{Pi}$. The figure is modified from original [31]. $2 P E$ two-photon excitation, STED stimulated emission depletion, $(F-)$ $P A L M$ (Fluorescence-) photo-activation localization microscopy, STORM stochastic optical reconstruction microscopy demonstrated in topical anti-QH1 antibody staining of quail embryos [16-22]. QH1 is expressed on the surface of quail endothelial cells [23]; superficially labeled endothelial cells were tracked as they migrate out from blood island pools, across extra-cellular matrix bridges, and around to form the cardio-vascular system [24, 25]. Widefield illumination allows for faster image acquisition-the entire field of view is excited at once. However, epifluorescent microscopy does not allow enough resolution in the $z$-axis to fully appreciate the cell movements involved in embryogenesis. Laser point-scanning microscopy methods such as confocal and two-photon excitation (2PE) do permit $3 \mathrm{D}$ resolution of the specimen. In particular, $2 \mathrm{PE}$ microscopy permits $150-300-\mu \mathrm{m}$ resolution in the $z$-axis in developing transgenic quail. In 2PE microscopy, ultra-short bursts of high intensity, longer-wavelength light (infra-red) excite fluorescent proteins or dyes that normally absorb a shorter wavelength of light [26]. Compared to confocal microscopy, the benefits of $2 \mathrm{PE}$ imaging include lowered cellular toxicity than confocal microscopy because infrared light interacts less with biological samples and fluorophore excitation is localized to the focal plane [26].

While epifluorescent, confocal, and 2PE microscopy are the most widely used imaging platforms, a number of modalities based on these techniques enable researchers to acquire volumetric images in multiple dimensions ( $x y z)$ and longitudinally over time $(t)$. Recent developments in high-speed aspects of fluorescent imaging make it possible to track and follow biological events ranging from cell/ tissue motion [20, 22, 27-29] down to molecule diffusion [30]. A compilation and comparison of various fluorescent microscopy techniques has recently been presented [31]. Figure 1 diagrams the application of various microscopy methods based on the dynamic process of interest. Briefly, the merits and contrasts between epifluorescence, confocal, and $2 \mathrm{PE}$ are given in Table 1.

Animal models

Where live imaging is concerned, an essential requirement is that the specimen continues to live and to function normally throughout the course of image acquisition. Successful specimen viability is made much more difficult

Table 1 Comparing and contrasting epifluorescent, confocal, and 2PE microscopy as live-imaging modalities

\begin{tabular}{|c|c|c|c|c|c|c|c|c|}
\hline $\begin{array}{l}\text { Imaging } \\
\text { modality }\end{array}$ & $\begin{array}{l}\text { Excitation } \\
\text { illumination }\end{array}$ & Detector & $\begin{array}{l}\mathrm{XY} \\
\text { resolution }\end{array}$ & $\mathrm{Z}$ resolution & $\mathrm{Z}$ penetration & $\begin{array}{l}\text { Temporal } \\
\text { resolution }\end{array}$ & $\begin{array}{l}\text { Photo- } \\
\text { bleaching }\end{array}$ & $\begin{array}{l}\text { Photo- } \\
\text { toxicity }\end{array}$ \\
\hline Epifluorescence & Uniform & 2D (e.g., CCD) & $* *$ & $*$ & $50 \mu \mathrm{m}$ & $* * *$ & $*$ & $*$ \\
\hline Confocal & Point scan & Point (e.g., PMT) & $* * *$ & $* *$ & $100 \mu \mathrm{m}$ & $* *$ & $* *$ & $* *$ \\
\hline $2 \mathrm{PE}$ & Point scan & Point (e.g., PMT) & $* * *$ & $* * *$ & $150-300 \mu \mathrm{m}$ & $* *$ & $* * / * * *$ & $*$ \\
\hline
\end{tabular}

Relative ranking points: * some, $* *$ more, $* * *$ most or even more 
by the requirements of imaging. The specimen must be incubated under physiological conditions, fit on a microscope stage, and remain relatively unaffected by constant imaging. The sample features best suited for live, dynamic imaging include optical clarity, small tissue size, fast development, and short biological activity time frames.

The zebrafish is a vertebrate model system particularly amenable to live imaging and developmental study. Embryos of this fish are readily accessible from large clutches, optically transparent, small in size $(\sim 1 \mathrm{~mm})$, and have a short developmental time $(\sim 72 \mathrm{~h})$. Other small multicellular organisms include urchin, nematode, and fly. Embryos may be immobilized for imaging by reducing culture temperature, utilizing anesthesia, or mounting in agarose molds [32]. Dynamic studies on organogenesis [33], lateral line migration [34-36], vascular development [37], and methods for gross or "in toto" embryonic development $[27,32]$ have been described in recent years in zebrafish. In Drosophila, Supatto et al. [28] describe the concerted movement of cells during gastrulation, modeling the fly embryo as a cylinder; while others document imaging border cell migration [38-40], documenting fine cell projections as border cells crawl within the developing embryo. These dynamic investigations are yielding dramatic insights into the process of morphogenesis, insights that could not have been realized with static imaging techniques.

To study more complex model systems, warm-blooded vertebrates such as mouse and avian, more intensive efforts are employed to access embryos and maintain them at physiological conditions. Murine embryos, while genetically well established, are ensconced in the uterus, thus quite difficult to visually access and require excision from the mother to fluorescently image. Laudable efforts, as demonstrated by Jones et al. [41] however, prove that it is possible to extract embryos from the uterine horn and culture them ex vivo for 18-24 h.

With the quail-and-chick model systems, embryos are more accessible and may be imaged either in ovo [42] or ex ovo [22, 43, 44]. Depending on the stages being studied, avian embryos can tolerate as many as $36 \mathrm{~h}$ of continuous imaging. The ex ovo technique utilizes a paper ring structure to mount the embryo. The embryo is then cultured on a thin agarose bed at temperatures of $32-37^{\circ} \mathrm{C}$. This setup is amenable to upright or inverted microscopy. Embryos may also be maintained in their native shell or in a surrogate shell $[45,46]$. In ovo techniques, employing a Teflon window can be used to visually access dorsal side tissue in the developing specimen [42]. With this method, the embryo is visible until day 4; beyond that, the embryo sinks down into the yolk, beyond the working distance of the microscope objective.

While they do not qualify as animal models, singlecell organisms such as bacteria and slime mold are relatively amenable to imaging due to both the ease in sample prep and genetic manipulation. Bacterial colonies are simply prepared between a glass coverslip and an agarose pad. Time-lapse microscopy in $E$. coli has been used to characterize cell shape dynamics [47], chromosome motility [48], and to quantitatively analyze gene feedback circuits [49]. The early time-lapse micrographs on the slime mold $D$. discoideum were pioneered by John Bonner [50, 51]. Slime molds have a short life cycle and are easily grown on agarose. Many of these time lapses show incredible cell behavior, both at the individual and collective level [52]. These early studies revealed that slime mold exhibits tissue polarity in collective tip movement and a pacemaker-like timing in tissue migration patterns $[53,54]$.

\section{Sample considerations}

\section{Fluorescent markers}

The subtleties of sample preparation aside, a major component to live imaging is choosing the appropriate fluorescent reporter. A few fluorescent reporters are specific to sub-cellular features, such as the vital nuclear stains Syto11 [55] and Hoechst 33342. However, because these dyes work by intercalating into the DNA, they disrupt DNA replication and are potentially mutagenic. Therefore, they should be tested in the system of interest for toxic effects. Fluorescent lipophilic dyes such as DiO and DiI vitally label plasma membranes and have been used to track and fate map cells during avian development [56, 57]. Dye conjugated to dextran, a membrane impermeant polysaccharide molecule, has been used to label and track the timing and pathways of avian trunk neural crest cell migration [58]. These studies demonstrated that there is a common precursor for both neural crest and neural tube cells; and that the rate and extent of cell migration varies throughout development.

Optional organic dyes employed for live imaging include fluoresceins [59], rhodamines [58], cyanine dyes (i.e., Cy3, Cy5) [60], and the commercial BODIPY and Alexa-Fluor dyes (Life Technologies). In addition to organic dyes, inorganic quantum dots can efficiently label molecules, proteins, and both fixed and live tissue [61-63]. However, penetrating and delivering labels throughout the sample is more difficult to do with topical dye and quantum dot application.

Fluorescently labeled antibodies were introduced as early as 1941 [2] and have been utilized widely to label and study dynamic processes in vitro. Libraries of fluorescent antibodies against cellular organelles, for example, are available commercially (Life Technologies). Many of these 
antibodies do not appear to affect normal cell behavior and thus can be used for dynamic imaging.

First cloned from the jellyfish Aequorea victoria in 1992, wild-type GFP has an excitation peak at 395/475 nm, borderline to the UV region [64]. As UV light can be toxic to living tissue and requires some special optics consideration (most optics are designed for use at visible wavelengths), efforts were made to create an improved GFP version. The resulting variant, enhanced GFP (EGFP), had a point mutation (S65T) which shifted the excitation peak into the cyan region at $488 \mathrm{~nm}$ [65]. EGFP was also brighter, thermally stable at $37^{\circ} \mathrm{C}$, and codon optimized. Additional variants have since been developed with excitation and emission maxima throughout the visible spectrum [66, 67]. The discovery of a red fluorescent protein in the coral Discosoma striata yielded DsRed [68], subsequent variations of monomeric DsRed [69], and the "fruit" FPs, named for various fruit that share the same color [70, 71]. The development of these spectrally resolvable fluorophores affords not only a choice in color, but opens the door to multi-color labeling.

By choosing the appropriate dichroic and band-pass filters, combinations of these encodable fluorophores may be utilized and discerned. A short list of some popular FPs and their relative brightness is compiled in Table 2. For multiple color experiments, colors can be chosen and spectrally resolved with computational linear unmixing [72], or by choosing colors with low crosstalk signal. In any case, every effort should be made to employ the brightest fluorophores possible, as photon counts will influence image collection rates and image quality. Commercial microscope optics allow for reasonable separation between cyan, yellow, orange, and red FPs. As progress is made on developing red and far-red emitting FPs [67, 73],

Table 2 A brief comparison of FPs [70, 93, 94]

\begin{tabular}{llll}
\hline & $\begin{array}{l}\text { Exc max } \\
(\mathrm{nm})\end{array}$ & $\begin{array}{l}\text { Em max } \\
(\mathrm{nm})\end{array}$ & $\begin{array}{l}\text { Relative } \\
\text { brightness }(\%)\end{array}$ \\
\hline mCherry & 587 & 610 & 47 \\
mApple & 568 & 592 & 109 \\
mRuby & 558 & 605 & 117 \\
DsRed & 558 & 583 & 176 \\
dTomato-Tandem & 554 & 581 & 283 \\
mCitrine & 516 & 529 & 174 \\
EYFP & 514 & 527 & 151 \\
Emerald & 487 & 509 & 116 \\
EGFP & 488 & 507 & 100 \\
Cerulean & 433 & 475 & 79 \\
ECFP & 439 & 476 & 39 \\
\hline
\end{tabular}

Relative brightness was calculated as a product of molar extinction coefficient and quantum yield and was normalized as percent brightness against EGFP the color palette may increase. In addition, advanced FP labeling experiments may be achieved by using optical highlighters such as photo-activatable [74], photo-switchable [75], and photo-convertible [74, 76, 77] proteins.

\section{Labeling strategy}

For longevity studies, employing endogenously expressed FPs over dyes or quantum dots is preferred. Where dyes are susceptible to photo-bleaching and dilution as cells divide, FP fusions can be expressed under continuously active promoters. In addition, FPs can be engineered to express using tissue specific promoters that are active at discrete spatial and temporal spaces.

Depending on the dynamic target of interest, there are a number of methods and options to express and localize FPs to a variety of cell populations and sub-cellular features. Chemical transfection, viral vector, DNA injection, RNA injection, and electroporation are just a few of the methods available to induce FP expression. For short-duration timelapse experiments, transient FP expression may be sufficient. Via transfection, injection, or electroporation of DNA, FP expression may appear as early as 3-6 h and last a few days. For long-term studies or experiments in very fresh tissue (less than $6 \mathrm{~h}$ ), stably integrated FP transgenesis may be required. Viral vectors such as retrovirus and lentivirus often require longer times before fluorescence is seen, usually 8-24 h. This time delay corresponds to cell division and breakdown of the nuclear envelope, which is required for the proviral genome to access and integrate into the host genome [78].

The biological behavior under observation will also dictate the optimal FP expression strategy. In tracking gross cell movement, FPs may be targeted to nuclei by fusion to histone or nucleoporin proteins. Fluorescently labeled nuclei have the added advantage in post-imaging analysis to be modeled as spheres or "spots" that can be tracked as cells migrate. Labeling the cell membrane enhances imaging of individual cells during migration and highlights cell activity as it senses the surrounding environment and chooses new directions. As an example, movies of GFP-labeled endothelial cells in zebrafish beautifully captured path-finding behavior and filopodial extensions of cells during angiogenesis, behavior similar to neuronal growth cones [79].

However, samples containing a high density of cells with either fluorescent cytoplasm or cell membrane run into problems with distinguishing cells from one another. This is especially true for monochromatic time-lapse experiments. A few solutions exist. FP expression may be driven by RNA polymerase II tissue-specific promoters to reduce the number of expressing cells, or electroporation may be used to induce a more "mosaic" expression. 
Alternatively, poly-chromatic or multi-spectral experiments may be set up to help distinguish between tightly packed individual cells, as nicely demonstrated by Jeff Lichtman's lab [80, 81].

\section{Imaging setup}

Various model organisms and tissue samples each have specific requirements for sustained survival during timelapse imaging: mainly temperature and air composition (see above section for references to individual species lines). In regards to time-lapse imaging, proper frame rate is one of the most important variables to determine. By imaging too slow, you can miss out on capturing the behavior of interest, and imaging too fast can lead to overstimulation of the sample and photo-toxicity or photobleaching. However, physical limits on speed of imaging are often related to hardware and camera capture rate or laser scan-head speed. The easiest way to determine the appropriate frame rate to capture the biological process of interest is empirical. Qualitatively, if an object of interest, say a cell nucleus, cannot be reliably identified between two subsequent frames in a time-lapse experiment, the frame rate should be increased.

To calculate the appropriate frame rate quantitatively, the velocity $v$ of the object in question should first be calculated, empirically, if needed. It is then assumed that image acquisition conditions (scan speed for point scanning confocal microscopes; image pixel density; image field of view) are such that the object is well resolved within a single snapshot (no blurring, good signal-tonoise). Next, a tolerance in tracking an object of size $\Delta \mathbf{x}$ with a motion resolution of $\boldsymbol{\Delta} \mathbf{x}^{\prime}$ should be identified. The desired frame rate $\boldsymbol{f}$ can then be calculated by $\boldsymbol{f}=\boldsymbol{v} / \boldsymbol{\Delta} \mathbf{x}^{\prime}$ [31]. In the example of tracking migrating cells, a labeled nucleus $(10 \mu \mathrm{m})$ may be tracked with a tolerable motion resolution $\Delta \mathrm{x}^{\prime}$ of $1 / 10(1 \mu \mathrm{m})$. That is, between two subsequent time-lapse frames, the nucleus is measured to move $1 \mu \mathrm{m}$. If cell migration velocity is determined to be $1.7 \times 10^{-2} \mu \mathrm{m} / \mathrm{s}(\sim 60 \mu \mathrm{m} / \mathrm{h})$, then the required frame rate is 1 frame per minute. Care should be taken, however, to ensure that the specimen does not suffer phototoxicity from constant bombardment of excitation light. Phototoxic effects can be avoided by either reducing the frame rate, choosing red or far-red excitable fluorophores, or employing 2PE microscopy. The longer wavelength excitation sources used for red and 2PE excitable fluorophores are lower in energy and, in general, are less toxic.

As experiments gain complexity in multi-dimensionality ( $x y z t \lambda$, where $\lambda$ is color), however, this tolerance in motion resolution may need to be sacrificed. Imaging in multiple color channels, in multiple sections of $z$ (for confocal or two-photon microscopy), or in mosaic tiles (to increase the field of view) may result in time-point acquisition times that exceed $1 / f$. Mosaic tiling within a time-lapse experiment allows for sampling an increased $x y$ field of view. For studying biological processes that span a large area, such as embryogenesis and organogenesis, mosaic tiling may be the only way to comprehensively capture the cellular movements. In general, tiles are best collected as groups of Z-stacks with a nominal $(10 \%)$ overlap.

That is, in a $2 \times 1$ tiled Z-stack time-lapse experiment, the Z-stack at position $(1,1)$ is collected; a piezo-motorized stage moves the specimen to the next position; and the Z-stack at position $(2,1)$ is collected. An overlap between tiles is ideal, as it aids in the reconstruction, or stitching together, of tiles post-acquisition.

In time-lapse imaging, dynamic processes are studied, so it is not uncommon to capture artifacts or detect mismatches after the stitching process. If the acquisition time for a Z-stack at $(1,1)$ is sufficiently long, the living specimen may move a detectable amount before the Z-stack at $(2,1)$ is taken. In some scenarios, the artifact may be irreparable and analysis of events residing in the overlap zone should be done with careful consideration and doublechecked manually.

Commercially available programs like Adobe Photoshop can stitch 2D images together in an automated fashion, however, fail when image content is low, as in sparsely labeled cell specimen or neuron tract tracing. Also, such programs are not equipped to handle 3D data sets. Another commercially available program, Zeiss AxioVision, can perform semi-automated stitching based on the a priori knowledge of the microscope stage position and alignment tiles to a reference $\mathrm{Z}$ slice. The program, however, will not stitch together data stacks with differing sizes in the Z-dimension. Examples of free stitching tools, such as GluMRC and LinkMRC employ a truer sort of 3D stitching in that individual landmarks are identified by the user and utilized to generate stitched images [82]. These programs can be time-intensive for the user, however, and require prior knowledge of the image landmarks. A more recent development, XuvTools employs heavier analysis methods that automatically compare image displacements between mosaics to generate stitched data sets [83].

While commendable advances have been made to recombine $3 \mathrm{D}$ data sets, user-friendly handling of stitched 4D data sets is still underway. The most advanced software available to date is the commercial Bitplane Imaris. Provided that each time point image has the same dimensions $(x, y, z)$, Imaris can read and process a 4D data set; nonuniformly sized data sets cannot be read. Strict and straightforward stitching of tiles, by AxioVision for example, results in uniform data set sizes that can be viewed and analyzed by Imaris. Engineering advances in image segmentation and tracking software [84, 85] may eventually 
provide efficient workarounds to easily process and analyze 4D data sets.

\section{Multi-spectral 4D imaging}

Both conventional confocal laser scanning microscopy and 2PE laser scanning microscopy offer the ability to volumetrically image multiple labels in the same specimen; however, quantitative imaging is best performed if the contribution from each dye can be cleanly separated from one another and from auto-fluorescence. Fortunately, the performance of multi-spectral techniques in living embryos is excellent, permitting clean separation of the emission from several different fluorescent proteins and/or dyes [86]. Alternatively, the spectra can be computationally unmixed to isolate the signals from each of the multiple dyes [72]. Color co-localization algorithms permit the image sets to be analyzed and precursor cells color-coded based on their origins to be distinctly evaluated and followed.

There are a number of instances in which multiple fluorophores would be utilized. In fluorescence resonance energy transfer (FRET), protein-protein interactions can be reported by energy transfer events between fluorophores, dyes or FPs. The FRET pair CFP-YFP has been used to report protease activity [87]. BFP-EGFP was used to monitor intracellular changes in $\mathrm{Ca}^{2+}$ levels $[88,89]$ by fusing BFP and EGFP to calmodulin and a calmodulinbinding peptide in MLCK. BFP-EGFP fusions to Bcl-2 and Bax, respectively, were used to demonstrate the protein interactions during cell apoptosis [90]. More recently, EGFP and mRFP were modified [91] to serve as FRET pair reporters to dynamic Rac1 activity in live $\mathrm{T}$ cell cultures [92].

Use of multiple colors is also useful for simultaneously labeling subcellular structures, such as plasma membrane and nucleus [86]. In the example of embryonic quail vasculogenesis, topical application of Cy3-labeled antiQH1 antibody against a $\mathrm{Tg}($ tie $1: \mathrm{H} 2 \mathrm{~B}-\mathrm{eYFP})$ quail embryo allows for simultaneous tracking of individual endothelial cells (by nuclei) and detailed observation of cell migratory behavior (by plasma membrane). Tissue-specific, multispectral labels within a developing embryo also provide information on gross morphogenetic processes. Crossing quail lines $\operatorname{Tg}($ tie $1: \mathrm{H} 2 \mathrm{~B}-\mathrm{eYFP}) \times \mathrm{Tg}(\mathrm{h} P G K: \mathrm{H} 2 \mathrm{~B}-\mathrm{mCherry})$ allows endothelial cell migration to be visualized against other tissues in the background (Lansford et al. Unpublished data). In specimen where cell density is very high, such as in the brain, multi-spectral labeling of cells may aid in differentiating and tracking individual cells. Identifying and tracking neurons in the Brainbow mice is an ideal example of this point [81].

\section{Technical aspects of data analysis}

The reality of advanced, multi-dimensional, time-lapse imaging is that large amounts (10-100 GBs) of data will be generated. These parameters all contribute toward file size: multiple color channels, 2D image resolution, number of $Z$-planes per stack, number of time points, and number of tiles per time point. To note, these parameters also impact the time required to acquire a single static image and dictate the lower limit of the time-lapse imaging frequency.

For efficient processing, these large data sets are passed through a data pipeline, such as the one given in Fig. 2 for tracking cell nuclei during Drosophila gastrulation [28]. Briefly, the specimen prep and imaging conditions addressed above are employed to collect time-lapse data sets. These sets are then visualized using imaging software such as Bitplane's Imaris or ImageJ that computationally identify and segment fluorescent objects. Next, the data is run through customized algorithms, commonly in MAT$\mathrm{LAB}$, to register the data spatially and temporally. For
Fig. 2 Data pipeline. Experimental work-flow describing image acquisition, manipulation, and analysis. In this example, embryos are prepared as needed (grey box), then undergo 4D imaging via confocal microscopy (green box). Post-acquisition, a combination of image-analysis software such as Imaris and MATLAB scripts (*.m) allow for $3 \mathrm{D}$ cell tracking (orange box), followed by temporal tracking (blue box), and finally data analysis (yellow box) (courtesy of Willy Supatto, modified from paper [95])

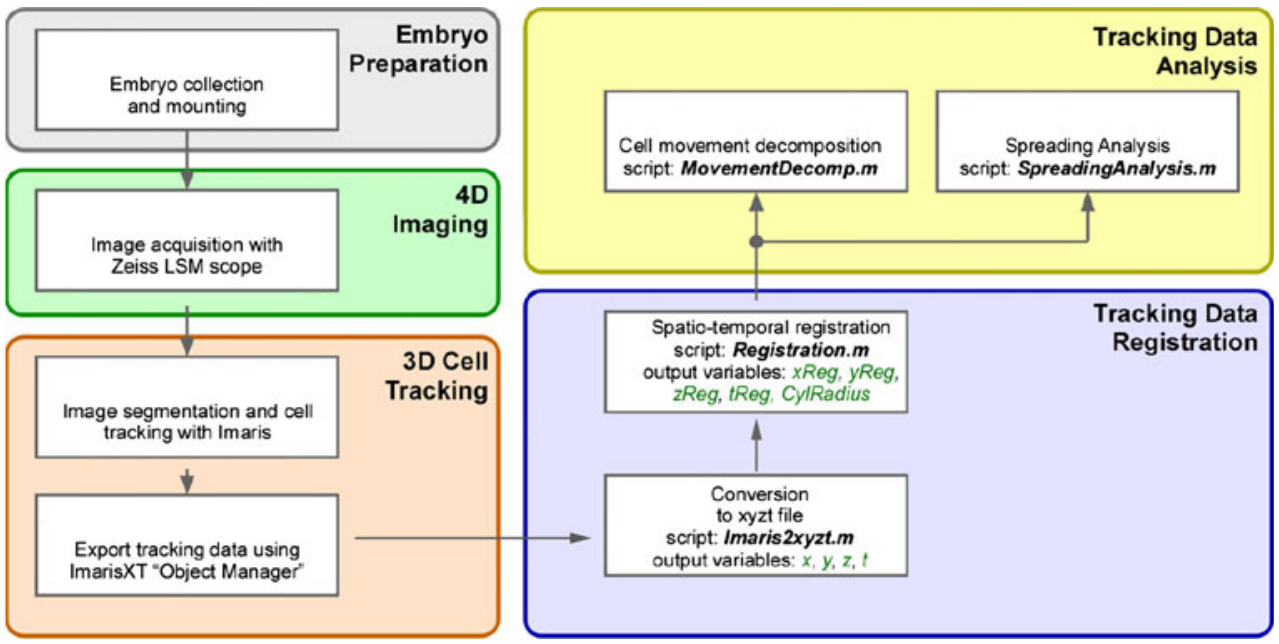



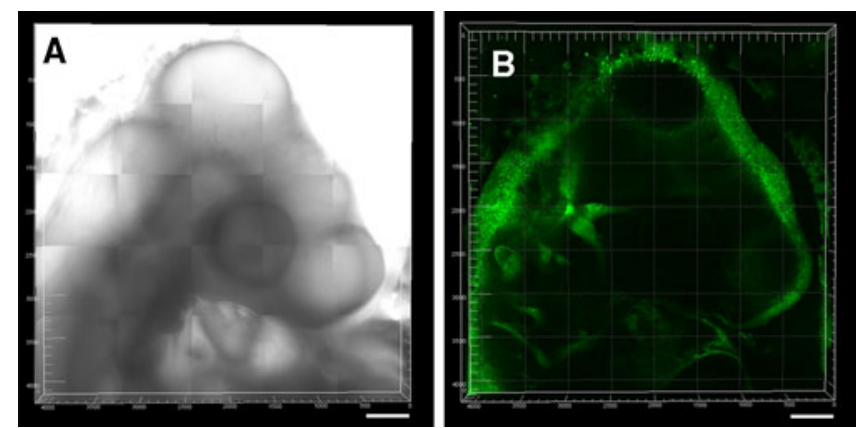

Fig. 3 Multi-dimensional imaging examples. a-c Tiled $5 \times 5$ Z-stack static image of $\operatorname{Tg}(S y n$ :EGFP) quail embryo. Neuronal cells express EGFP. Images acquired on a Zeiss 510 META inverted confocal microscope. Objective used: Plan-Apochromat 10X/0.45NA. Zeiss Multi-time Macro acquired and stitched the 3D data together. Stitched images are displayed in brightfield (a), GFP channel (b), and merge (c). Scale bar $500 \mu \mathrm{m}$. Z stack: 121 stacks; $363 \mu \mathrm{m}$ deep. d Imaris manipulation and analysis of 4D data. Cell migrations during

example, registration algorithms might be applied to a data set to correct for sample drift within the field of view over the duration of the time-lapse experiment. After registration, analytical information may be mined, such as cell count, mitotic rates, gene expression over time, cell velocity, or mean displacement. As an example, individual cells during sea urchin gastrulation can be tracked and fatemapped using advanced, time-lapse microscopy techniques (Fig. 3; Mat Barnet (Biological Imaging Center, Caltech, unpublished data)).

\section{Conclusions}

Thanks to contributions from physics, engineering, and computer science, the biologist's toolbox has been expanded with advances in microscope hardware, labeling strategies, and computational power. These resulting techniques in time-lapse imaging are revolutionizing our insights into dynamic processes, from intracellular trafficking to in toto embryo development. We gain new perspectives and increased dimensionality in viewing living systems: in space, in time, in color. As these tools continue to develop, their application promises to deliver a deeper understanding into biology and development.

Acknowledgments A grant from NIH CEGS (P50 HG004071) supported this review. The authors gratefully thank Mat Barnet for his contribution of sea urchin images, Willy Supatto for his pipeline figures, and Dave Huss for his discussions on ex ovo culture systems.

Open Access This article is distributed under the terms of the Creative Commons Attribution Noncommercial License which permits any noncommercial use, distribution, and reproduction in any medium, provided the original author(s) and source are credited.
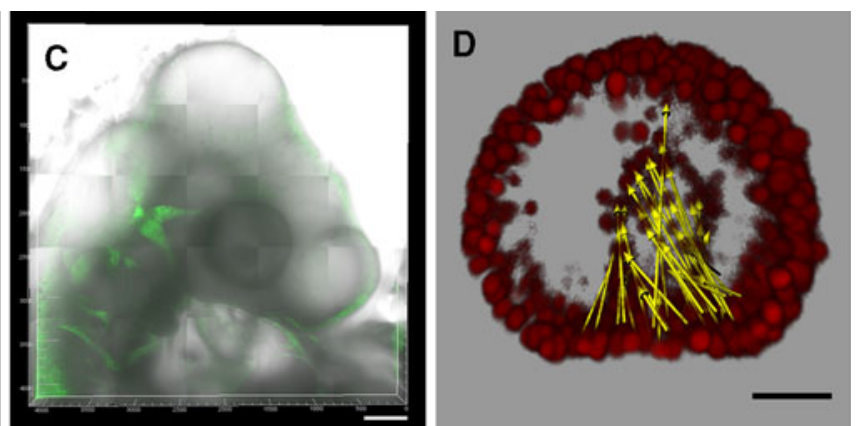

sea urchin embryo gastrulation over $12 \mathrm{~h}$ of development were analyzed. Cells were labeled by injecting at the one-cell stage mRNA encoding a nuclear-localized RFP. The embryo was imaged in 4D using a Zeiss confocal microscope. Arrows show the net movement of selected nuclei fated to form the primitive gut. Portions of the ectoderm have been computationally removed, leaving the projection of a $50-\mu \mathrm{m}$ slab of the embryo that includes the forming endoderm. Scale bar $20 \mu \mathrm{m}$ (sea urchin image courtesy of Mat Barnet)

\section{References}

1. Amos WD, White JG (2003) How the confocal laser scanning microscope entered biological research. Biol Cell 95:335-342

2. Kasten FH (1989) The origin of modern fluorescence microscopy. chap 1. Academic Press, San Diego

3. Lazarides E, Weber K (1974) Actin antibody: the specific visualization of actin filaments in non-muscle cells. Proc Natl Acad Sci USA 71:2268

4. Tsien RY, Rink TJ, Poenie M (1985) Measurement of cytosolic free $\mathrm{Ca}^{++}$in individual small cells using fluorescence microscopy with dual excitation wavelengths. Cell Calcium 6:145-157

5. White JG (1987) Confocal scanning microscope. UK Patent Application

6. Minsky M (1988) Memoir on inventing the confocal scanning microscope. Scanning 10:128-138

7. Nakano A (2002) Spinning-disk confocal microscopy-a cuttingedge tool for imaging of membrane traffic. Cell Struct Funct 27:349-355

8. Kozubek M, Matula P, Matula P, Kozubek S (2004) Automated acquisition and processing of multidimensional image data in confocal in vivo microscopy. Microsc Res Tech 64:164-175

9. Wang E, Babbey C, Dunn K (2005) Performance comparison between the high-speed Yokogawa spinning disc confocal system and single-point scanning confocal systems. J Microsc 218:148-159

10. Denk W, Strickler JH, Webb WW (1990) Two photon laser scanning fluorescence microscopy. Science 248:73-76

11. Denk W, Delaney KR, Gelperin A (1994) Anatomical and functional imaging of neurons using 2-photon laser scanning microscopy. J Neurosci Methods 54:151-162

12. Bewersdorf J, Pick R, Hell SW (1998) Multifocal multiphoton microscopy. Opt Lett 23:655-657

13. Piston DW (1999) Imaging living cells and tissues by two-photon excitation microscopy. Trends Cell Biol 9:66-69

14. Gratton E, Barry NP, Beretta S, Celli A (2001) Multiphoton fluorescence microscopy. Methods 25:103-110

15. Diaspro A, Chirico G, Collini M (2005) Two-photon fluorescence excitation and related techniques in biological microscopy. Q Rev Biophys 38:97-166

16. Little CD, Drake CJ (2000) Whole-mount immunolabeling of embryos by microinjection. Increased detection levels of 
extracellular and cell surface epitopes. Methods Mol Biol 135:183-189

17. Czirok A, Rupp PA, Rongish BJ, Little CD (2002) Multi-field 3D scanning light microscopy of early embryogenesis. J Microsc 206:209-217

18. Rupp PA, Rongish BJ, Czirok A, Little CD (2003) Culturing of avian embryos for time-lapse imaging. Biotechniques 34:274-278

19. Czirok A, Rongish BJ, Little CD (2004) Extracellular matrix dynamics during vertebrate axis formation. Dev Biol 268:111-122

20. Filla MB, Czirok A, Zamir EA, Little CD, Cheuvront TJ, Rongish BJ (2004) Dynamic imaging of cell, extracellular matrix, and tissue movements during avian vertebral axis patterning. Birth Defects Res C Embryo Today 72:267-276

21. Cui C, Lansford R, Filla MB, Little CD, Cheuvront TJ, Rongish BJ (2006) Electroporation and EGFP labeling of gastrulating quail embryos. Dev Dyn 235:2802-2810

22. Zamir EA, Czirok A, Cui C, Little CD, Rongish BJ (2006) Mesodermal cell displacements during avian gastrulation are due to both individual cell-autonomous and convective tissue movements. Proc Natl Acad Sci USA 103:19806-19811

23. Pardanaud L, Altmann C, Kitos P, Dieterlen-Lievre F, Buck CA (1987) Vasculogenesis in the early quail blastodisc as studied with a monoclonal antibody recognizing endothelial cells. Development 100:339-349

24. Wagner RC (1980) Endothelial cell embryology and growth. Adv Microcirc 9:45-75

25. Little CD, Rongish BJ (1995) The extracellular matrix during heart development. Experientia 51:873-882

26. Williams RM, Piston DW, Webb WW (1994) Two-photon molecular excitation provides intrinsic 3-dimensional resolution for laser-based microscopy and microphotochmistry. FASEB J 8:804-813

27. Keller PJ, Schmidt AD, Wittbrodt J, Stelzer EHK (2008) Reconstruction of zebrafish early embryonic development by scanned light sheet microscopy. Science 322:1065-1069

28. McMahon A, Supatto W, Fraser SE, Stathopoulos A (2008) Dynamic analyses of Drosophila gastrulation provide insights into collective cell migration. Science 322:1546-1550

29. Sato Y, Watanabe T, Saito D, Takahashi T, Yoshida S, Kohyama J, Ohata E, Okano H, Takahashi Y (2008) Notch mediates the segmental specification of angioblasts in somites and their directed migration toward the dorsal aorta in avian embryos. Dev Cell 14:890-901

30. Eggeling C, Ringemann C, Medda R, Schwarzmann G, Sandhoff K, Polyakova S, Belov VN, Hein B, von Middendorff C, Schönle A, Hell SW (2009) Direct observation of the nanoscale dynamics of membrane lipids in a living cell. Nature 457:1159-1162

31. Vermot J, Fraser SE, Liebling M (2008) Fast fluorescence microscopy for imaging the dynamics of embryonic development. HFSP J 2:143-155

32. Megason SG (2009) In toto imaging of embryogenesis with confocal time-lapse microscopy. Methods Mol Biol 546:317-332

33. Vasilyev A, Liu Y, Mudumana S, Mangos S, Lam PY, Majumdar A, Zhao J, Poon KL, Kondrychyn I, Korzh V, Drummond IA (2009) Collective cell migration drives morphogenesis of the kidney nephron. PLoS Biol 7:e9

34. Aman A, Piotrowski T (2008) Wnt/ $\beta$-Catenin and Fgf signaling control collective cell migration by restricting chemokine receptor expression. Dev Cell 15:749-761

35. Lecaudey V, Cakan-Akdogan G, Norton WH, Gilmour D (2008) Dynamic FGF signaling couples morphogenesis and migration in the zebrafish lateral line primordium. Development 135:2695-2705

36. Nechiporuk A, Raible DW (2008) FGF-dependent mechanosensory organ patterning in zebrafish. Science 320:1774

37. Kamei M, Weinstein BM (2005) Long-term time-lapse fluorescence imaging of developing zebrafish. Zebrafish 2:113-123
38. Bianco A, Poukkula M, Cliffe A, Mathieu J, Luque CM, Fulga TA, Rørth P (2007) Two distinct modes of guidance signalling during collective migration of border cells. Nature 448:362365

39. Prasad M, Montell DJ (2007) Cellular and molecular mechanisms of border cell migration analyzed using time-lapse live-cell imaging. Dev Cell 12:997-1005

40. Tekotte H, Tollervey D, Davis I (2007) Imaging the migrating border cell cluster in living Drosophila egg chambers. Dev Dyn 236:2818-2824

41. Jones EA, Crotty D, Kulesa PM, Waters CW, Baron MH, Fraser SE, Dickinson ME (2002) Dynamic in vivo imaging of postimplantation mammalian embryos using whole embryo culture. Genesis 34:228-235

42. Kulesa P, Bronner-Fraser M, Fraser S (2000) In ovo time-lapse analysis after dorsal neural tube ablation shows rerouting of chick hindbrain neural crest. Development 127:2843-2852

43. New D (1955) A new technique for the cultivation of the chick embryo in vitro. J Embryol Exp Morphol 3:320-331

44. Chapman S, Collignon J, Schoenwolf GC, Lumsden A (2001) Improved method for chick whole-embryo culture using a filter paper carrier. Dev Dyn 220:284-289

45. Kamihira M, Oguchi S, Tachibana A, Kitagawa Y, Iijima S (1998) Improved hatching for in vitro quail embryo culture using surrogate eggshell and artificial vessel. Dev Growth Diff 40:449

46. Naito M, Sano A, Kawashima T, Nakamichi H, Harumi T, Matsubara Y, Kuwana T (2005) Culture of chicken embryos obtained from the anterior region of the magnum of the oviduct after removing a thin layer of dense albumen capsule from the ovum. J Poult Sci 42:369:374

47. Reshes G, Vanounou S, Fishov I, Feingold M (2008) Cell shape dynamics in Escherichia coli. Biophys J 94:251-264

48. Espeli O, Mercier R, Boccard F (2008) DNA dynamics vary according to macrodomain topography in the E. coli chromosome. Mol Microbiol 68:1418-1427

49. Rosenfeld N, Young JW, Alon U, Swain PS, Elowitz MB (2007) Accurate prediction of gene feedback circuit behavior from component properties. Mol Syst Biol 3:143

50. Bonner JT (1944) A descriptive study of the development of the slime mould Dictyostelium discoideum. Am J Bot 31:175-182

51. Bonner JT (1959) The cellular slime molds (Investigations in the biological sciences). Princeton University Press, Princeton

52. Gerisch G (1968) Cell aggregation and differentiation in Dictyostelium. Academic Press, New York

53. Durston AJ (1974) Pacemaker activity during aggregation in Dictyostelium discoideum. Dev Biol 37:225-235

54. Durston AJ, Vork F (1979) A cinematographical study of the development of vitally stained Dictyostelium discoideum J. Cell Sci 36:261-279

55. O'Roarke NA, Chenn A, McConnell SK (1997) Postmitotic neurons migrate tangentially in the cortical ventricular zone. Development 124:997-1005

56. Krull CE, Collazo A, Fraser SE, Bronner-Fraser M (1995) Segmental migration of trunk neural crest: time-lapse analysis reveals a role for PNA-binding molecules. Development 121:3733-3743

57. Krull CE, Lansford R, Gale NW, Collazo A, Marcelle C, Yancopoulos GD, Fraser SE, Bronner-Fraser M (1997) Interactions of Eph-related receptors and ligands confer rostrocaudal pattern to trunk neural crest migration. Curr Biol 7:571-580

58. Serbedzija GN, Bronner-Fraser M, Fraser SE (1994) Developmental potential of trunk neural crest cells in the mouse. Development 120:1709-1718

59. Keith CH, Feramisco JR, Shelanski M (1981) Direct visualization of fluorescein-labeled microtubules in vitro and in microinjected fibroblasts. J Cell Biol 88:234-240 
60. Waggoner A (1979) The use of cyanine dyes for the determination of membrane potentials in cells, organells, and vesicles. Methods Enzymol 55:689-695

61. Jaiswal JK, Mattoussi H, Mauro JM, Simon SM (2003) Longterm multiple color imaging of live cells using quantum dot bioconjugates. Nat Biotechnol 21:47-51

62. Larson DR, Zipfel WR, Williams RM, Clark SW, Bruchez MP, Wise FW, Webb WW (2003) Water-soluble quantum dots for multiphoton fluorescence imaging in vivo. Science 300:14341436

63. Michalet X, Pinaud FF, Bentolila LA, Tsay JM, Doose S, Li JJ, Sundaresan G, Wu AM, Gambhir SS, Weiss S (2005) Quantum dots for live cells, in vivo imaging, and diagnostics. Science 307:538-544

64. Prasher DC, Eckenrode VK, Ward WW, Prendergast FG, Cormier MJ (1992) Primary structure of the Aequorea victoria greenfluorescent protein. Gene 111:229-233

65. Heim R, Cubitt A, Tsien R (1995) Improved green fluorescence. Nature 373:663-664

66. Ormö M, Cubitt AB, Kallio K, Gross LA, Tsien RY, Remington SJ (1996) Crystal structure of the Aequorea victoria green fluorescent protein. Science 273:1392-1395

67. Mishin AS, Subach FV, Yampolsky IV, King W, Lukyanov KA, Verkhusha VV (2008) The first mutant of the Aequorea victoria green fluorescent protein that forms a red chromophore. Biochemistry 47:4666-4673

68. Matz MV, Fradkov AF, Labas YA, Savitsky AP, Zaraisky AG, Markelov ML, Lukyanov SA (1999) Fluorescent proteins from nonbioluminescent Anthozoa species. Nat Biotechnol 17:969-973

69. Campbell RE, Tour O, Palmer AE, Steinbach PA, Baird GS, Zacharias DA, Tsien RY (2002) A monomeric red fluorescent protein. Proc Natl Acad Sci USA 99:7877-7882

70. Shaner NC, Campbell RE, Steinbach PA, Giepmans BN, Palmer AE, Tsien RY (2004) Improved monomeric red, orange and yellow fluorescent proteins derived from Discosoma $s p$. red fluorescent protein. Nat Biotechnol 22:1567-1572

71. Wang L, Jackson WC, Steinbach PA, Tsien RY (2004) Evolution of new nonantibody proteins via iterative somatic hypermutation. Proc Natl Acad Sci USA 101:16745-16749

72. Dickinson ME, Bearman G, Tille S, Lansford R, Fraser SE (2001) Multi-spectral imaging and linear unmixing add a whole new dimension to laser scanning fluorescence microscopy. Biotechniques 31(1272):1274-1276, 1278

73. Shcherbo D, Merzlyak EM, Chepurnykh TV, Fradkov AF, Ermakova GV, Solovieva EA, Lukyanov KA, Bogdanova EA, Zaraisky AG, Lukyanov S, Chudakov DM (2007) Bright far-red fluorescent protein for whole-body imaging. Nat Meth 4:741-746

74. Patterson G, Lippincott-Schwartz J (2002) A photoactivatable GFP for selective photolabeling of proteins and cells. Science 297:1873-1877

75. Habuchi S, Tsutsui H, Kochaniak AB, Miyawaki A, van Oijen AM (2008) mKikGR, a monomeric photoswitchable fluorescent protein. PLoS ONE 3:e3944

76. Chudakov D, Belousov V, Zaraisky A, Novoselov V, Staroverov D, Zorov D, Lukyanov S, Lukyanov K (2003) Kindling fluorescent proteins for precise in vivo photolabeling. Nat Biotechnol 21:191-194

77. Mizuno H, Mal T, Tong K, Ando R, Furuta T, Ikura M, Miyawakil A (2003) Photo-induced peptide cleavage in the green-tored conversion of a fluorescent protein. Mol Cell, pp 1051-1058

78. LaRue AC, Lansford R, Drake CJ (2003) Circulating blood island-derived cells contribute to vasculogenesis in the embryo proper. Dev Biol 262:162-172
79. Lawson ND, Weinstein BM (2002) In vivo imaging of embryonic vascular development using transgenic zebrafish. Dev Biol 258:307-318

80. Feng G, Mellor RH, Bernstein M, Keller-Peck C, Nguyen QT, Wallace M, Nerbonne JM, Lichtman JW, Sanes JR (2000) Imaging neuronal subsets in transgenic mice expressing multiple spectral variants of GFP. Neuron 28:41-51

81. Livet J, Weissman TA, Kang H, Draft RW, Lu J, Bennis RA, Sanes JR, Lichtman JW (2007) Transgenic strategies for combinatorial expression of fluorescent proteins in the nervous system. Nature 450:56-62

82. Karen P, Jirkovska M, Tomori Z, Demjenova E, Janacek J, Kubınova L (2003) Three-dimensional computer reconstruction of large tissue volumes based on composing series of high-resolution confocal images by gluemrc and linkmrc software. Microsc Res Tech 62:415-422

83. Emmenlauer M, Ronneberger O, Ponti A, Schwarb P, Griffa A, Filippi A, Nitschke R, Driever W, Burkhardt H (2009) XuvTools: free, fast and reliable stitching of large 3D datasets. J Microsc 233:42-60

84. Dufour A, Shinin V, Tajbakhsh S, Guillen-Aghion Olivo-MarinJ-C (2005) Segmenting and tracking fluorescent cells in dynamic 3-D microscopy with coupled active surfaces. IEEE Trans Image Process 14:1396-1410

85. Berlemont S, Olivo-Marin J-C (2010) Combining local filtering and multiscale analysis for edge, ridge, and curvilinear objects detection. IEEE Trans Image Process 19:74-84

86. Teddy JM, Lansford R, Kulesa PM (2005) Four-color, 4-D timelapse confocal imaging of chick embryos. Biotechniques 39:703710

87. Heim R, Tsien RY (1996) Engineering green fluorescent protein for improved brightness, longer wavelengths and fluorescence resonance energy transfer. Curr Biol 6:178-182

88. Miyawaki A, Llopis J, Heim R, McCaffrey J, Adams J, Ikura M, Tsien R (1997) Fluorescent indicators for $\mathrm{Ca}^{2+}$ based on green fluorescent proteins and calmodulin. Nature 388:882-887

89. Rosomer V, Hinkle P, Persechini A (1997) Detection in living cells of $\mathrm{Ca}^{2+}$ dependent changes in the fluorescence emission of an indicator composed of two green fluorescent protein variants linked by a calmodulin-binding sequence: a new class of fluorescent indicators. J Biol Chem 272:13270-13274

90. Majahan N, Linder K, Gail B, Gordon GW, Heim R, Herman B (1998) Bcl-2 and Bax interactions in mitochondria probed with green fluorescent protein and fluorescence resonance energy transfer. Nat Biotechnol 16:547-552

91. Itoh R, Kurokawa K, Fujioka A, Sharma A, Mayer B, Matsuda M (2005) A FRET-based probe for epidermal growth factor receptor bound non-covalently to a pair of synthetic amphipathic helixes. Exp Cell Res 307:142-152

92. Matthews DR, Carlin LM, Ofo E, Barber PR, Vojnovic B, Irving M, Ng T, Ameer-Beg SM (2010) Time-lapse FRET microscopy using fluorescence anisotropy. J Microsc 237:51-62

93. Shaner NC, Steinbach PA, Tsien RY (2005) A guide to choosing fluorescent proteins. Nat Methods 2:905-909

94. Kredel S, Oswald F, Nienhaus K, Deuschle K, Röcker C, Wolff M, Heilker R, Nienhaus GU, Wiedenmann J (2009) mRuby, a bright monomeric red fluorescent protein for labeling of subcellular structures. PLoS ONE 4:e4391

95. Supatto W, McMahon A, Fraser SE, Stathopoulos A (2009) Quantitative imaging of collective cell migration during Drosophila gastrulation: multiphoton microscopy and computational analysis. Nat Protoc 4:1397-1412 